\title{
ANALISIS TITIK IMPAS USAHATANI PADI BERSERTIFIKAT ORGANIK (Studi kasus pada Kelompok Tani Tirta Rahayu di Desa Sukanagara Kecamatan Padaherang Kabupaten Pangandaran)
}

\author{
BREAK EVEN ANALYSIS OF ORGANIC CERTIFIED PADDY FARMING \\ (Case Study on Tirta Rahayu Farmers Group in Sukanagara Village, Padaherang District, \\ Pangandaran Regency)
}

\author{
SURMAN $^{1 *}$, MUHAMAD NURDIN YUSUF ${ }^{1}$, DANI LUKMAN HAKIM ${ }^{1}$ \\ ${ }^{1}$ Fakultas Pertanian, Universitas Galuh \\ *E-mail : sansukebe@ gmail.com
}

\begin{abstract}
ABSTRAK
Penelitian ini bertujuan untuk mengetahui besarnya: (1) biaya yang dikeluarkan dalam usahatani padi bersertifikat organik per hektar per satu musim tanam pada Kelompok Tani Tirta Rahayu, (2) pendapatan dalam usahatani padi bersertifikat organik per hektar per satu musim tanam pada Kelompok Tani Tirta Rahayu, (3) titik impas dalam usahatani padi bersertifikat organik per hektar per satu musim tanam pada Kelompok Tani Tirta Rahayu. Jenis penelitian yang digunakan dalam penelitian ini adalah metode studi kasus, dengan mengambil kasus pada Kelompok Tani Tirta Rahayu di Desa Sukanagara Kecamatan Padaherang Kabupaten Pangandaran. Jumlah responden yang diambil adalah seluruh anggota kelompok sebanyak 25 orang petani dengan menggunakan metode sampling jenuh atau sensus. Hasil penelitian ini memperlihatkan bahwa : 1. Besarnya biaya yang dikeluarkan dalam usahatani padi bersertifikat organik per hektar per satu musim tanam di Desa Sukanagara adalah sebesar : Rp 8.182.507,45, 2. Besarnya pendapatan pada usahatani padi padi bersertifikat organik per hektar per satu musim tanam di Desa Sukanagara adalah sebesar : Rp 13.263.252,35, 3. Besarnya titik impas pada usahatani padi padi bersertifikat organik per hektar per satu musim tanam di Desa Sukanagara adalah sebagai berikut: nilai penjualan (BEPnp) adalah Rp 1.584.398,18, titik impas volume produksi (BEPvp) adalah sebanyak 211,25 kilogram. Titik impas luas lahan (BEPLL) adalah seluas 0,07 hektar dan titik impas harga adalah Rp 2.861,58.
\end{abstract}

Kata Kunci : Padi organik, titik impas, usahatani

\begin{abstract}
The study aimed to know: (1) costs incurred in certified organic paddy farming per hectare per one growing season in Tirta Rahayu Farmers Group, (2) revenues in certified organic paddy farming per hectare per one growing season in Tirta Tani Group Rahayu, (3) break-even point in certified organic paddy farming per hectare per planting season in the Tirta Rahayu Farmer Group. The type of research used in this study was the case study method, on the Tirta Rahayu Farmer Group in Sukanagara Village, Padaherang District, Pangandaran Regency. The number of respondents taken were all group members, i.e 25 farmers using the saturated sampling method or census. The results of this study showed that: 1) the amount of costs incurred in certified organic paddy farming per hectare per one planting season in Sukanagara Village was: Rp 8,182,507.45, 2)the amount of income on organic certified paddy farming per hectare per one The planting season in Sukanagara Village was: $R p 13,263,252.35,3)$ the break-even point on certified organic paddy farming per hectare per planting season in Sukanagara Village was as following: Sales value (BEP $n p$ ) was Rp. 1,584,398.18, break even production volume (BEP vp) was 211.25 kilograms. Break-even point of land area (BEPLL) covering an area of 0.07 hectares and the break even point of price was Rp 2,861.58.
\end{abstract}

Keywords: Break even, farming, organic paddy 


\section{PENDAHULUAN}

Peran penting sektor pertanian terhadap perekonomian nasional berupa pendapatan devisa negara di luar minyak dan gas bumi serta dalam perekonomian rakyat tidak bisa diabaikan. Disamping itu tidak kalah pentingnya sektor pertanian, khususnya tanaman pangan mempunyai peran strategis dalam menjaga stabilitas negara melalui ketersediaan dan ketahanan pangan (Direktorat Jenderal Tanaman Pangan , 2017).

Kebijakan pembangunan pertanian terfokus pada peningkatan produktivitas pangan khususnya padi. Sistem produksi yang baik untuk peningkatan produksi tanpa menimbulkan kerusakan ekosistem adalah tanpa penggunaan bahan kimia agar pertanian dapat berkelanjutan. Pertanian organik merupakan pengimplementasian berusahatani secara alami tanpa penggunakan pupuk kimia dan pestisida, serta pengolahan tanah yang sedikit mungkin, tetapi dengan hasil yang sama dengan pertanian konvensional (Sutanto, 2002).

Kabupaten Pangandaran merupakan salah satu kabupaten di Jawa Barat yang memiliki potensi dalam pembudidayaan padi organik. Menurut informasi Dinas Pertanian Kabupaten Pangandaran (2019) Desa Sukanagara Kecamatan Padaherang merupakan salah satu desa yang melaksanakan usahatani padi bersertifikat organik dengan luas lahan paling besar yaitu 7,3 hektar.

Usahatani padi bersertifikat organik masih tergolong baru dan belum dikenal para petani dan masyarakat luas, khususnya petani di Desa Sukanagara Kecamatan Padaherang. Supaya usahatani padi bersertifikat organik pada Kelompok Tani "Tirta Rahayu” lebih berkembang dan tidak mengalami kerugian, maka diperlukan informasi mengenai titik impas dari penjualan, titik impas dari volume produksi dan minimal luas lahan yang harus diusahakan dalam berusahatani. Sehubungan hal tersebut penulis merasa tertarik untuk menganalisa titik impas usahatani padi bersertifikat organik pada Kelompok Tani Tirta Rahayu di Desa Sukanagara Kecamatan Padaherang Kabupaten Pangandaran.

Berdasarkan uraian tersebut maka penelitian ini bertujuan untuk : (1)Mengetahui rata-rata biaya yang dikeluarkan petani per hektar dalam satu kali musim tanam, (2) Mengetahui ratarata penerimaan serta pendapatan yang diterima petani per hektar per satu kali musim tanam, (3) Mengetahui rata-rata titik impas usahatani padi bersertifikat 
organik per hektar per satu kali musim tanam.

\section{METODE PENELITIAN}

\section{Jenis Penelitian}

Penelitian ini dilakukan dengan menggunakan metode studi kasus, dengan mengambil kasus pada usahatani padi bersertifikat organik pada Kelompok Tani "Tirta Rahayu" di Desa Sukanagara Kecamatan Padaherang Kabupaten Pangandaran. Studi kasus merupakan penelitian mengenai status suatu subjek penelitian yang berhubungan dengan suatu sesi spesifik atau unik dari keseluruhan personalitas. Subjek penelitian dapat berupa masyarakat, kelompok, keluarga, maupun individu (Nazir, 2011).

\section{Operasionalisasi Variabel}

Variabel-variabel yang dipergunakan dalam penelitian ini dioperasionalisasikan sebagai berikut :

1. Pertanian organik merupakan suatu sistem pertanian yang memicu pembentukan tanah dan tanaman yang sehat dengan melaksanakan implementasi budidaya tanaman seperti recycle hara pada bahan-bahan organik, perputaran tanaman, pengolahan tanah yang benar dan menghindari penggunaan pupuk dan pestisida sintetik.
2. Satu musim tanam adalah dimulai dari menyediakan bibit, mengolah lahan, menanam, merawat tanaman hingga panen.

3. Biaya total (total cost) adalah semua biaya yang dipergunakan dalam berusahatani padi organik, dihitung dalam satu kali musim tanam, dan dinilai dalam satuan rupiah (Rp). Biaya produksi meliputi :

1. Biaya Tetap (fixed cost) adalah biaya yang tidak dipengaruhi jumlah produksi dan bersifat tidak habis dalam satu kali musim tanam, dinilai dalam satuan rupiah per hektar per satu musim tanam. Biaya tetap meliputi :

a. Pajak bumi dan bangunan (PBB) dihitung dalam satuan rupiah per meter persegi $\left(\mathrm{Rp} / \mathrm{m}^{2}\right)$.

b. Penyusutan alat dihitung dalam satuan rupiah $(\mathrm{Rp})$ per hektar per satu kali musim tanam. Untuk mengetahui besar penyusutan alat dihitung mempergunakan rumus (Suratiyah, 2006) :

Penyusutan Alat= Nilai Pembelian - Nilai Sisa Umur Ekonimis

Nilai sisa merupakan nilai pada waktu alat tersebut sudah tidak dapat digunakan. 
c. Bunga modal dihitung dalam satuan persen bersumber pada bunga bank yang berlaku ketika penelitian, dinilai dalam satuan rupiah $(\mathrm{Rp})$.

2. Biaya variabel merupakan biaya yang sangat tergantung pada faktor produksi dan sifatnya habis setiap satu kali musim tanam, dihitung dalam satuan rupiah per hektar per satu kali musim tanam. Biaya variabel meliputi :

a. Biaya benih merupakan biaya yang digunakan untuk membeli benih yang dihitung dalam satuan rupiah per hektar per satu kali musim tanam (Rp/ha/mt).

b. Biaya pupuk organik merupakan biaya yang digunakan untuk pembelian pupuk organik dihitung dalam satuan rupiah per hektar per satu musim tanam (Rp/ha/mt).

c. Biaya POC merupakan biaya yang digunakan untuk membeli POC dihitung dalam satuan rupiah per hektar per satu kali musim tanam (Rp/ha/mt).

d. Biaya pestisida nabati merupakan biaya yang digunakan untuk membeli pestisida nabati dihitung dalam satuan rupiah perhektar per satu kali musim tanam (Rp/ha/mt).

e. Biaya tenaga kerja adalah biaya untuk membayar seluruh tenaga kerja yang dicurahkan dalam usahatani yang dikonversikan ke dalam Hari Kerja Setara Pria (HKSP), dan dinilai dalam satuan rupiah per hektar per satu kali musim tanam (Rp/ha/mt).

3. Hasil produksi merupakan hasil berusahatani padi organik dan dihitung satuan kilogram per hektar per satu musim tanam.

4. Harga jual merupakan harga dari produk dan dihitung dalam satuan rupiah per kilogram.

5. Penerimaan merupakan perkalian antara harga jual dengan hasil produksi , dinilai dalam satuan rupiah (Rp) per hektar per satu musim tanam.

6. Pendapatan adalah selisih antara penerimaan dengan pembiyaan produksi yang dikeluarkan dan dihitung dalam satuan rupiah $(\mathrm{Rp})$ per hektar per satu kali musim tanam.

7. Titik impas (BEP) adalah suatu keadaan usahatani yang dijalankan tidak mendapatkan keuntungan tetapi 
juga tidak mengalami kerugian, titik impas terdiri atas :

a. BEP nilai penjualan merupakan suatu kondisi usahatani dimana nilai penerimaan dari usahatani yang dijalankan tidak mendapatkan keuntungan namun tidak mengalami kerugian.

b. BEP volume produksi adalah suatu kondisi usahatani dimana jumlah produksi yang dihasilkan dari usahatani yang dijalankan tidak mengalami keuntungan tetapi tidak mengalami kerugian.

c. BEP luas lahan adalah luas lahan keseluruhan yang digunakan dalam usahatani yang dijalankan tidak mengalami kerugian tetapi tidak mendapatkan keuntungan.

d. Titik impas harga (BEPH) adalah harga terendah yang harus diterima petani agar usahatani tidak mengalami kerugian namun tidak mendapatkan keuntungan.

Asumsi yang dipergunakan selama penelitian ini adalah :

1. Semua hasil produksi habis terjual.

2. Harga jual produk ketika penelitian tetap.
3. Sarana produksi yang dipergunakan habis terpakai dalam satu kali proses produksi.

4. Harga input per unit ketika penelitian tetap.

\section{Teknik Pengumpulan Data}

Data yang dipergunakan dalam penelitian ini meliputi :

1. Data primer, data ini didapatkan dari hasil wawancara langsung dengan responden dengan menggunakan kuesioner yang sudah dipersiapkan sebelumnya, dan melakukan observasi lapangan.

2. Data sekunder, diperoleh dari instansi maupun dinas terkait serta pustaka yang ada hubungannya dengan penelitian ini.

\section{Teknik Penarikan Sampel}

Jumlah sampel ditentukan menggunakan metode sampling jenuh atau sensus, dimana seluruh anggota kelompok tani Tirta Rahayu dijadikan sampel semua yaitu sebanyak 25 orang. Menurut Sugiyono (2009), teknik penentuan sampel ketika semua anggota populasi dijadikan sampel disebut dengan sampel jenuh.

\section{Rancangan Analisis Data}

Data yang terkumpul ditabulasi dan dianalisis secara deskriptif mempergunakan analisis usahatani yang 
meliputi analisis titik impas. Analisis data dimaksudkan dijabarkan sebagai berikut :

1. Analisis Biaya

Untuk mengetahui jumlah biaya total (total cost) yang dikeluarkan petani adalah dengan cara penjumlahan antara biaya tetap (Total Fixed Cost/FC) dengan biaya variabel (Total Variable Cost) dengan rumus sebagi berikut (Suratiyah, 2006):

$\mathrm{TC}=\mathrm{TFC}+\mathrm{TVC}$

Dimana :

TC : Total biaya (total cost)

TFC : Total biaya tetap (total fixed cost)

TVC : Total biaya variabel (total variable cost)

2. Analisis penerimaan

Untuk mengetahui peneriman total (Total Revenue/TR) adalah dengan perkalian antara jumlah total produksi dengan harga jual satuan produk yang diperoleh petani dalam berusahatani padi organik mempergunakan rumus sebagai berikut (Suratiyah, 2006) :

$\mathrm{TR}=\mathrm{Y} . \mathrm{Hy}$

Dimana :

TR : Penerimaan (total revenue)

Y : Jumlah produksi

Hy : Harga produk

3. Analisis Pendapatan
Pendapatan adalah selisis antara penerimaan total (Total Revenue/TR) dengan biaya total (Total Cost/TC) digunakan rumus sebagai berikut (Suratiyah, 2006) : $\pi=\mathrm{TR}-\mathrm{TC}$

Dimana :

$\pi$ : Pendapatan (Rp)

TR : Penerimaan total (Rp)

TC : Biaya total (biaya total)

4. Untuk mengetahui titik impas (Break Even Point) dihitung mempergunakan rumus sebagai berikut (Suratiyah, 2006) :

a. BEP penerimaan $(\mathrm{Rp})$ :

$$
\text { BEPnp }=\frac{\text { Biaya tetap total }}{1-\frac{\text { Biaya variabel }}{\text { Nilai penjualan }}}
$$

b. BEP volume produksi $(\mathrm{kg})$ :

$$
\mathrm{BEP} v \mathrm{p}=\frac{\mathrm{BEP} \text { penerimaan }}{\text { Harga }(\mathrm{Rp} \mathrm{kg})}
$$

c. BEP luas lahan ( ha) :

$$
\text { BEP luas lahan }=\frac{\text { BEPvp }}{\text { Produktivitas }}
$$

d. Titik Impas harga (Rp/kg) :

$$
\text { BEP harga }(\mathrm{Rp} / \mathrm{kg})=\frac{\text { Biaya Total }}{\text { Produktivitas }}
$$

\section{Tempat dan Waktu Penelitian}

Penelitian ini dilaksanakan di Desa Sukanagara Kecamatan Padaherang Kabupaten Pangandaran pada bulan April sampai Juli 2019. 
HASIL

PENELITIAN

DAN

PEMBAHASAN

\section{Identitas Responden}

Responden dalam penelitian ini adalah petani yang berusahatani padi bersertifikat organik pada Kelompok Tani Tirta Rahayu di Desa Sukanagara Kecamatan Padaherang yang berjumlah 25 orang. Indikator yang digunakan dalam menjelaskan identitas responden meliputi umur, tingkat pendidikan, tanggungan keluarga, pengalaman berusahatani dan luas lahan garapan.

\section{Umur Responden}

Umur responden berkisar antara 35 sampai 63 tahun dengan demikian responden tergolong pada usia produktif. Hal ini sesuai dengan pendapat Wirosuharjo (2004) yang menyatakan bahwa yang dimaksud dengan penduduk usia produktif adalah penduduk yang berusia antara 15 sampai 64 tahun. Umur berpengaruh terhadap kemampuan fisik dan juga respon petani terhadap inovasi.

2. Pendidikan Responden

Tingkat pendidikan formal yang diraih oleh petani dapat dilihat pada Tabel 1 .
Tabel 1. Tingkat Pendidikan Responden

\begin{tabular}{rlrr}
\hline No & $\begin{array}{c}\text { Pendidikan } \\
\text { formal }\end{array}$ & $\begin{array}{r}\text { Jumlah } \\
\text { (orang) }\end{array}$ & $\begin{array}{c}\text { Persentase } \\
(\boldsymbol{\%})\end{array}$ \\
\hline 1 & SD/MI & 8 & 32 \\
2 & SMP & 8 & 32 \\
3 & SMA & 9 & 36 \\
& Jumlah & $\mathbf{2 5}$ & $\mathbf{1 0 0}$ \\
\hline
\end{tabular}

Tabel 1 menunjukkan pendidikan responden ternyata lebih didominasi oleh tamatan SMA, hal ini setidaknya menggambarkan tingkat pedidikan yang berhasil ditamatkan oleh petani cukup tinggi atau berada pada tingkat pendidikan menengah. Tingkat pendidikan sangat berpengaruh terhadap wawasan petani dalam berusahatani. Tingginya tingkat pendidikan ini merupakan indikator kenapa responden mau untuk melakukan usaha tani padi sawah organik.

3. Pengalaman Usahatani

Pengalaman berusahatani responden berkisar antara 3-11 tahun, dengan ratarata 3,4 tahun. Hal ini menunjukan bahwa responden masih baru dalam melakukan usahataninya, hal ini ditunjang oleh fakta di lapangan bahwa usahatani padi organik di Kelompok Tani Tirta Rahayu baru diperkenalkan tahun 2007, sementara untuk pensertifikatan baru dilaksanakan tahun 2015 dan mendapatkan sertifikat pertanian organik dari inofice 
(Indonesian Organic Farming

Certification) pada tahun 2018.

4. Tanggungan Keluarga

Tanggungan keluarga merupakan salah satu unsur motivasi bagi petani dalam menjalankan usahataninya. Dengan kegiatan usahataninya, petani berharap mampu memenuhi kebutuhan keluarganya. Adapun jumlah tanggungan keluarga dari responden dapat dilihat pada Tabel 2.

\section{Tabel 2. Jumlah Tanggungan Keluarga}

\begin{tabular}{cccc}
\hline No & $\begin{array}{c}\text { Tanggungan } \\
\text { Keluarga }\end{array}$ & $\begin{array}{c}\text { Jumlah } \\
\text { (orang) }\end{array}$ & $\begin{array}{c}\text { Pesentase } \\
(\boldsymbol{\%})\end{array}$ \\
\hline 1 & $\leq 3$ & 18 & 72 \\
2 & $>3$ & 7 & 28 \\
& Jumlah & $\mathbf{2 5}$ & $\mathbf{1 0 0}$ \\
\hline
\end{tabular}

Berdasarkan Tabel 2, terlihat bahwa mayoritas responden memiliki tanggungan keluarga $\leq 3$ orang. Hal ini setidaknya menggambarkan anggapan secara umum masyarakat di perdesaan tentang banyak anak banyak rejeki sudah tidak lagi diyakini.

5. Luas Lahan

Luas lahan yang digunakan usahatani padi bersertifikat organik sangat bervariasi antara 0,03 hektar sampai 1,97 hektar dengan rata-rata luas lahan 0,29 hektar. Adapun jumlah kepemilikan lahan dapat dilihat pada Tabel 3.

\section{Tabel 3. Identitas Responden Berdasarkan Kepemilikan Lahan}

\begin{tabular}{cccc}
\hline No & $\begin{array}{c}\text { Luas Kepemilikan } \\
\text { Lahan } \\
\text { (ha) }\end{array}$ & $\begin{array}{c}\text { Jumlah } \\
\text { (orang) }\end{array}$ & $\begin{array}{c}\text { Persenta } \\
\text { se } \\
(\boldsymbol{\%})\end{array}$ \\
\hline 1 & $\leq 0,25$ & 17 & 68 \\
2 & $>0,25$ & 8 & 32 \\
& Jumlah & 25 & 100 \\
\hline
\end{tabular}

Berdasarkan Tabel 3 dapat terlihat bahwa responden lebih didominasi oleh petani kecil. Sebagimana pendapat Soekartawi dalam Shinta (2012) bahwa petani kecil merupakan petani yang hanya menggarap lahan kurang dari 0,25 hektar untuk lahan sawah atau 0,5 hektar untuk lahan tegalan.

\section{Analisis Biaya Usahatani Padi Organik}

Biaya dalam berusahatani padi organik merupakan biaya yang dikeluarkan selama proses produksi, antara lain biaya tetap dan biaya tidak tetap. Biaya tetap dalam usahatani padi sawah meliputi biaya pajak lahan, penyusutan alat serta biaya bunga modal. Adapun rata-rata biaya dalam berusahatani padi organik dapat dilihat pada Tabel 4. 
Tabel 4. Rata-rata Biaya pada Usahatani Padi Organik per hektar per Musim Tanam

\begin{tabular}{|c|c|c|c|}
\hline o & Biaya & $\begin{array}{c}\text { Jumlah } \\
\text { Biaya (Rp) }\end{array}$ & $\begin{array}{c}\text { Persentase } \\
(\%)\end{array}$ \\
\hline 1 & Pajak Lahan & $50.068,80$ & 0,61 \\
\hline 2 & Penyusutan Alat & $332.359,26$ & 4,06 \\
\hline \multirow[t]{2}{*}{3} & Bunga Modal 7\% & $675.619,88$ & 8,26 \\
\hline & Biaya Tetap Total & $1.058 .047,94$ & 12,93 \\
\hline \multicolumn{4}{|c|}{4 Biaya Saprodi } \\
\hline & Benih & $603.630,00$ & 7,38 \\
\hline & Pupuk Kompos & $1.067 .860,80$ & 13,05 \\
\hline & POC & $403.560,00$ & 4,93 \\
\hline & Pestisida Nabati & $85.500,00$ & 1,04 \\
\hline$J$ & $\begin{array}{l}\text { Biaya Tenaga } \\
\text { Kerja }\end{array}$ & $4.963 .908,71$ & 60,66 \\
\hline & aya Variabel Total & $7.124 .459,50$ & 87,07 \\
\hline & Biaya Total & $8.182 .507,45$ & 100 \\
\hline
\end{tabular}

Dari Tabel 10 dapat diambil kesimpulan bahwa biaya yang paling besar dikeluarkan untuk biaya tenaga kerja. Hal ini terjadi karena pengaplikasian mekanisasi pertanian masih kurang, sehingga dalam melakukan proses produksinya masih memerlukan banyak tenaga kerja.

\section{Analisis Penerimaan dan Pendapatan}

\section{Usahatani Padi Organik}

Penerimaan diperoleh dari perkalian jumlah produksi dengan harga jual. Ratarata produksi padi organik per hektar per musim tanam adalah 2.859,43 kilogram dengan harga jual $\mathrm{Rp}$ 7.500/kilogram, sehingga diperoleh penerimaan $\mathrm{Rp}$ 21.445.759,80. Sedangkan pendapatan merupakan hasil dari pengurangan penerimaan oleh biaya total. Jumlah biaya total adalah Rp 8.182.507,45 per hektar per satu kali musim tanam dengan demikian diperoleh pendapatan dengan jumlah $\mathrm{Rp}$ 13.263.252,35 per musim tanam.

\section{Analisis Titik Impas (Break Event Point) pada Usahatani Padi Organik}

1. Analisis Titik Impas Penerimaan (BEPnp)

Besar penerimaan minimum yang diterima petani agar usahataninya tidak mengalami kerugian dapat diketahui dengan cara sebagai berikut (Suratiyah, 2006) :

BEP penerimaan $($ BEPnp $)=\frac{\text { Biaya tetap total }}{1-\frac{\text { Biaya variabel }}{\text { Nilai penjualan }}}$

$$
\text { BEPnp }=\frac{1.058 .047,95}{1-\frac{7.124 .459,51}{21.445 .759,80}}
$$

BEPnp $=1.584 .398,18$

Hasil perhitungan menunjukkan bahwa penerimaan minimum yang harus diterima petani agar tidak mengalami kerugian dalam satu kali musim tanam adalah sebesar Rp 1.584.398,18

2. Analisis Titik Impas Volume Produksi (BEPvp)

Volume atau jumlah produksi minimum yang harus diperoleh untuk mencapai titik impas dalam satu kali musim 
tanam, maka digunakan rumus perhitungan (Suratiyah, 2006) :

BEPvp $=\frac{\text { BEP penerimaan }}{\text { Harga }(\mathrm{Rp} / \mathrm{kg})}$

$\mathrm{BEPvp}=\frac{1.584 .398,18}{7.500}$

BEPvp $=211,25$

Hasil perhitungan di atas menunjukkan bahwa volume atau jumlah roduksi yang harus diperoleh dari usahatani padi organik, agar mencapai titik impas adalah sebanyak 211,25 kilogram.

3. Analisis Titik Impas Luas Lahan

Luas lahan minimum usahatani padi organik yang harus diusahakan petani agar usahatani padi organik tidak menderita kerugian dalam satu musim tanam dapat diketahui cara (Suratiyah, 2006) :

BEP luas lahan $=\frac{\text { BEP volume produksi }}{\text { Produktivitas }}$ BEP luas lahan $=\frac{211,25}{2859,43}$

BEP luas lahan $=0,07$

Hasil perhitungan menunjukkan bahwa luas lahan minimum yang harus diusahakan agar mencapai titik impas adalah 0,07 hektar atau seluas 700 meter persegi.

4. Analisis Titik Impas Harga

Harga jual terendah yang harus dipertahankan agar petani tidak memperoleh kerugian dapat dihitung menggunakan rumus (Suratiyah, 2006) :

$\mathrm{BEP}$ harga $(\mathrm{Rp} / \mathrm{kg})=\frac{\text { Biaya total }}{\text { Produktivitas }}$

$\mathrm{BEP}$ harga $(\mathrm{Rp} / \mathrm{kg})=\frac{8.182 .507,45}{2859,43}$

BEP harga $(\mathrm{Rp} / \mathrm{kg})=2.861,58$

Hasil perhitungan menunjukkan bahwa harga minimum yang harus dipertahankan agar mencapai titik impas adalah $\operatorname{Rp} 2.861,58$.

\section{KESIMPULAN DAN SARAN}

Kesimpulan

Berdasarkan hasil penelitian dan pembahasan yang telah diuraikan sebelumnya, maka dapat disimpulkan :

1. Besarnya biaya dalam usahatani padi bersertifikat organik pada Kelompok Tani Tirta Rahayu di Desa Sukanagara Kecamatan Padaherang Kabupaten Pangandaran sebesar Rp 8.182.507,45 dengan penerimaan sebesar $\mathrm{Rp}$ 21.445.759,80, sehingga diperoleh pendapatan sebesar Rp 13.263.252,35 per hektar per musim tanam.

2. Besarnya titik impas nilai penjualan pada usahatani padi bersertifikat organik pada Kelompok Tani Tirta Rahayu di Desa Sukanagara Kecamatan Padaherang Kabupaten Pangandaran sebesar Rp 1.584.398,18 dengan titik impas volume produksi 
sebanyak 211,25 kilogram dengan BEP luas lahan 0,07 hektar dan BEP harga sebesar Rp 2.861,58.

\section{Saran}

Untuk lebih memaksimalkan pendapatan atau keuntungan petani padi bersertifikat organik di Kecamatan Padaherang, maka disarankan hal-hal sebagai berikut :

1) Produktivitas padi bersertifikat organik dengan menggunakan metode SRI (Sistem Of Rice Intensification) masih belum maksimal karena masih terdapat transisi lahan sawah dari konvensional menjadi organik sehingga perlu diperhatikan tentang pengembalian kesuburan tanah dan ekologi tanahnya.

2) Upaya untuk meningkatkan pendapatan petani padi bersertifikat organik pada Kelompok Tani Tirta Rahayu di Desa Sukanagara Kecamatan Padaherang Kabupaten Pangandaran hendaknya tidak menjual langsung hasil panen dalam bentuk gabah namun akan lebih baik dijadikan beras agar mendapat nilai tambah dan harga yang lebih bernilai ekonomis, dan mencari pangsa pasar yang lebih menguntungkan.

3) Koreksi harga jual dengan cara menurunkan harga diperlukan agar bisa mendapatkan konsumen yang lebih banyak namun tetap memperhatikan titik impas harga.

\section{DAFTAR PUSTAKA}

Dinas Pertanian Kabupaten Pangandaran. 2019. Laporan Tahunan. Pangandaran.

Direktorat Jenderal Tanaman Pangan Kementrian Pertanian. Laporan Kinerja. 2017.

Nazir, M. 2011. Metode Penelitian. Ghalia Indonesia, Bogor.

Shinta, A. 2011. Ilmu Usahatani. UB Press. Malang.

Sugiyono, 2009. Pengertian Teknik Sampling. Alfabeta. Bandung.

Suratiyah, K. 2006. Pengembangan Ilmu Usahatani. Penebar Swadaya. Jakarta.

Sutanto, 2002. Apa Itu Pertanian Organik ? Info Organis Biocert. Bogor.

Wirosuharjo. 2004. Dasar-Dasar Demografi. Fakultas Ekonomi Universitas Indonesia. Jakarta. 